\title{
The Optimal Camouflage Pattern Assessment and Design in all Conditions
}

\author{
Jianqiu $\mathrm{Yu}^{1}$, Zhe $\mathrm{Cao}^{1}$, \& Qiuping $\mathrm{Lai}^{1}$ \\ ${ }^{1}$ Anhui University of Finance \& Economic, Bengbu City, Anhui Province, China \\ Correspondence: Jianqiu Yu, Anhui University of Finance \& Economic, Bengbu City, Anhui Province, China. \\ E-mail: chinayujianqiu@163.com
}

Received: June 2, 2015 Accepted: June 10, 2015 Online Published: June 17, 2015

doi:10.5539/jmsr.v4n3p76 URL: http://dx.doi.org/10.5539/jmsr.v4n3p76

\begin{abstract}
As we all know, there are a large mount of camouflage patterns and complex terrains in the real world. Therefore, we classify the camouflage patterns and pick up five representative terrains firstly, After that, we establish five abstract models evaluating the low-efficiency of camouflage patterns and set corresponding indexes to establish the quantitative relationship between patterns and effect. Then, we acquire the consequence by programming in MATLAB. Furthermore, we use the fuzzy comprehensive evaluation to maintain the best camouflage pattern in a single terrain and obtain the use frequency of different type of camouflage patterns in different terrains, the optimal camouflage patterns are discovered and designed in all terrains. Finally, combining with the above results, we make an advertising sheet for a website highlighting to show our design and the best camouflage effect.
\end{abstract}

Keywords: camouflage patterns, terrains, fuzzy comprehensive evaluation, MATLAB

\section{Problem Restatement}

\subsection{The Basic Background of the Problem}

Camouflage is composed of green, yellow, brown and black. It reflected wave and the surrounding scenery reflection of roughly the same. Not only confuse the enemy vision reconnaissance, but also deal with infrared reconnaissance. Causing the enemy to modernization as the detection instruments are difficult to capture target. Hitler's forces in the end of the world war two first use of camouflage, as the "three color camouflage". Later, some countries in America led "four-color camouflage equipment". Generally, at present the world is "six color camouflages". Modern camouflage also can base on the different needs of the basic color changes, with various patterns.

At present, there is no uniform criterion that how to comprehensively evaluate a camouflage pattern and choose the most appropriate camouflage pattern in different actual combat condition.

\subsection{The Problem Need to be Solved}

Question1: The effect of different kinds of camouflages in different environment is different, so the first thing need to be done is simply classifying all kinds of environment. Meanwhile, different kinds of camouflage should be collocated basing on the fundamental parameters of camouflage,

Question2: The establishment of five quantitative camouflage model,

Question3: Develop a model to analyze the influence of various camouflage patterns on the hiding effect, create a quantitative method to comprehensive analysis the effect of the camouflage,

Question4: To design an ideal fit most environment camouflage textile pattern; and combined with the practice. Prepare one or two page ad for a particular website and design the highlights of the camouflage patterns and camouflage effect.

\section{The Analysis of the Problem}

\subsection{The Introduction of Relevant Knowledge}

A kind of camouflage methods which Use paint, dye and other materials to change target, screen or the background color according to certain requirements and can be divided into deformation protective camouflage, Tran mutative camouflage and imitated camouflage three kinds. 
1) Protective camouflage, this is a monochromatic camouflage which is similar to the basic background color that can help to reduce the significance of the target, and it's used to camouflage the target on the monochromatic background. For example, the protecting camouflage should be green on the summer grass background; and be yellow on desert background, while be white on the snow background.

2) Tran mutative camouflage, this king of camouflage is composed of several large irregularly shaped spots that can distort the target shape and used to disguise multicolor background moving target, such as tanks, cars, guns, etc.

3) Imitated camouflage, this is a multicolor camouflage that Imitate the surrounding background speckle pattern in order Integrate the target in the background, which used for camouflage fixed targets on the multicolor background or long-stayed moving target .

\subsection{Analysis of the Problems of the Overall (Flow chart)}

Attributed to camouflage Patterns types and landform type is diversified, the relationship established between camouflage design and its camouflage performance need to carry on the simple classification for camouflage patterns at first, then select five kinds of basic terrain types, and set up five kind of camouflage patterns camouflage abstract evaluation model on this basis, following by setting the corresponding indicators, establish a camouflage patterns and the quantitative relationship between the camouflage effect. Again through the quantitative relationship and obtain data, and use the fuzzy comprehensive evaluation method, to conclude that the best camouflage patterns in different terrain.

Then using the analytic hierarchy process to obtain the using frequency of different types of camouflage patterns in different terrain, and discussed and designed the optimal camouflage patterns in all terrain as a result .Finally, combining the results above, the optimal camouflage patterns present in the form of advertising, highlights our design and camouflage effects, we applied the abstraction of the model to practice, to make the camouflage has guiding significance in modern society.

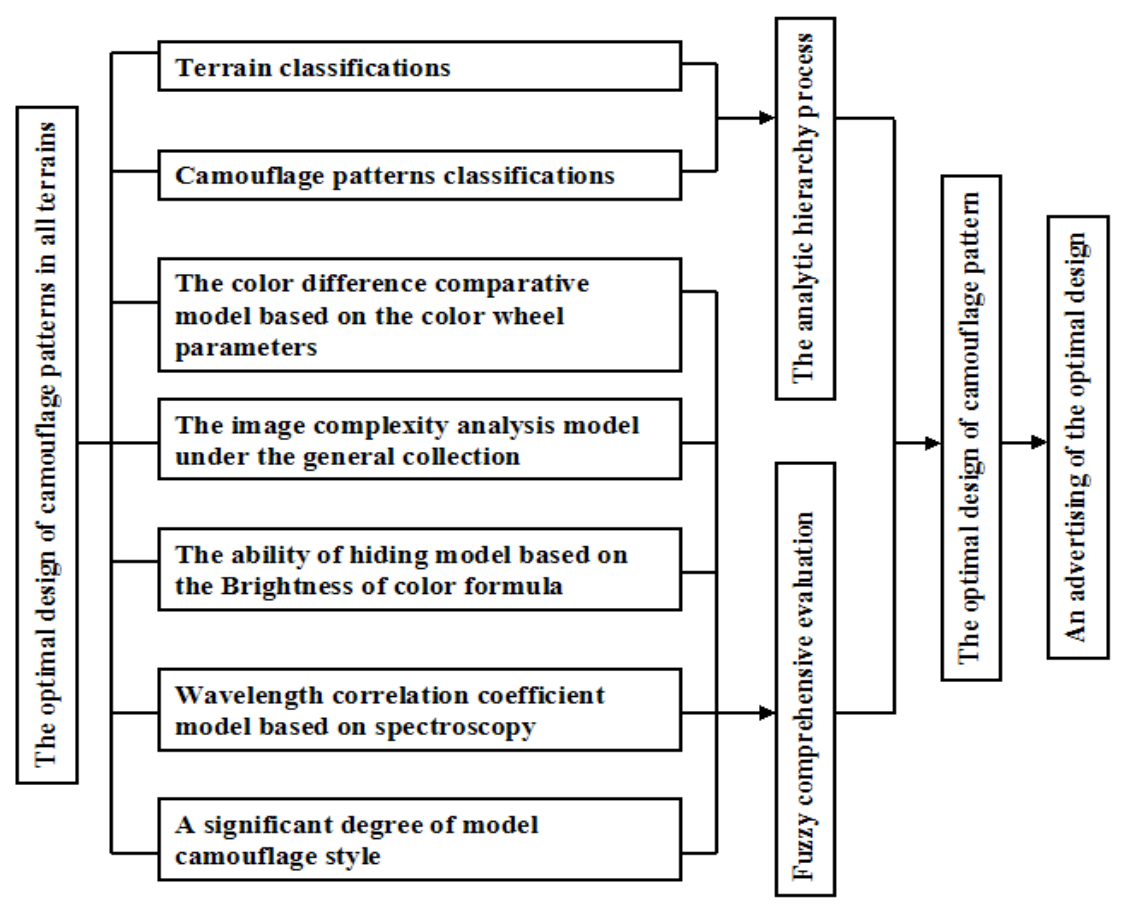

Figure 1. add figure title here

\section{The assumptions of the model.}

1) Ignoring the correlation effect between variables;

2) Visibility and perspective correspondence hypothesis in each environment with the same effect on the visual distance can be neglected; 
3) Assume that each of the types of color combinations of colors and the proportion of the same;

4) Effect of neglecting texture structure on the hiding effect;

5) the assumption that each Patterns color distribution of the same;

6) various color combinations are independent of each other, mutual influence;

7) Assuming that the visual distance refers to the visual distance, influence of optical reconnaissance instruments regardless of on the final hiding effect;

\section{The Explanation of the Proper Nouns and Symbols}

\subsection{The Explanation of Proper Nouns}

Hue Ring: a ring which is mainly composed of hues with five colors, six colors or twenty-four colors.

Color difference: referring to the size of discrimination between the color of camouflage patterns and terrains.

The complex of image: the representative value of the complexity of images. If the complex value is greater, the image contains more information such as colors, patterns, and the image is more complicated.

The absolute complex differences of images: the absolute value of the complex difference between camouflage patterns and topographic patterns. The less difference means the more similarity between camouflage patterns and topographic patterns.

Wavelength: referring to the distance of wave propagation in a vibration cycle. The wavelength of visible light ranges from $770 \mathrm{~nm}$ to $390 \mathrm{~nm}$. The electromagnetic with different kind of wavelengths lead to the different feeling of color for human eyes.

Significant degrees: human eye visual effect caused by the contrast relationship between the camouflage patterns and terrains due to the brightness and colors of camouflage.

\subsection{The Explanation of Symbols}

\begin{tabular}{|c|c|c|}
\hline Serial number & Symbol & Explanation \\
\hline 1 & $A_{i j}$ & Chromatic aberration between color $i$ and $j$ \\
\hline 2 & $\theta$ & The acute angle formed by the $\angle A O B$ \\
\hline 3 & $h$ & The length of the $B C$ \\
\hline 4 & $C$ & The image complexity \\
\hline 5 & $k$ & The number of pattern image contains \\
\hline 6 & $N$ & A number of gray level \\
\hline 7 & $n_{i}$ & The number of gray $i$ levels \\
\hline 8 & $h^{\prime}$ & $\begin{array}{l}\text { The absolute value of subtraction in complex value of Camouflage image and } \\
\text { topographic images }\end{array}$ \\
\hline 9 & $Y$ & Camouflage color brightness \\
\hline 10 & $R$ & The corresponding numerical for red \\
\hline 11 & $G$ & The corresponding numerical for green \\
\hline 12 & $B$ & The corresponding numerical for blue \\
\hline 13 & $Y_{1}$ & Camouflage color brightness \\
\hline 14 & $Y_{2}$ & Environmental color brightness \\
\hline 15 & $\gamma$ & Brightness percentage \\
\hline 16 & $r$ & Wavelength correlation coefficient \\
\hline 17 & $\bar{x}, \bar{y}$ & The mean \\
\hline 18 & $a_{i}$ & $\begin{array}{c}\text { The number } i \text { pattern of Patterns corresponds to "significantly" the most } \\
\text { significant degree of size }\end{array}$ \\
\hline 19 & $D$ & Observation distance \\
\hline 20 & $y_{i}$ & Relative color \\
\hline 21 & $y_{i}^{\prime}$ & The relative brightness \\
\hline 22 & $\alpha$ & The human point of view angle \\
\hline
\end{tabular}




\section{The Establishment of the Model and Solution}

\subsection{The Analysis and Solving of the Question 1}

\subsection{The Problem Put Forward}

Different Patterns camouflage pattern effect in different environment is different, but in real life the camouflage clothing Patterns and environment category is various, therefore, in order to facilitate the quantitative analysis of camouflage concealment performance, we must first carry out a brief abstract classification of the various types of environmental according to certain parameters; at the same time, different kinds of camouflage should be collocated basing on the fundamental parameters of camouflage.

\subsection{Analysis and Problem Solving}

\subsubsection{The Classification Problem in Camouflage}

On the basis of reading a lot of literature and field research, we put on all the camouflage color in the market collocation including brown, black, olive green, soil yellow and blue and all the camouflage patterns are made up of the combination of those three colors.

Table 1. Camouflage Patterns color matching table

\begin{tabular}{cccc}
\hline Camouflage patterns & \multicolumn{3}{c}{ Color Patterns } \\
\hline Patterns 1 & Brown & Black & olive green \\
Patterns 2 & Brown & black & yellow \\
Patterns 3 & Brown & black & blue \\
Patterns 4 & Brown & olive green & yellow \\
Patterns 5 & Brown & olive green & green \\
Patterns 6 & Brown & yellow & blue \\
Patterns 7 & Black & olive green & yellow \\
Patterns 8 & Black & olive green & blue \\
Patterns 9 & Black & yellow & blue \\
Patterns 10 & olive green & yellow & blue \\
\hline
\end{tabular}

\subsubsection{Terrain Classification}

Earth terrain is varied, but as a human activity area can only be divided into the following five kinds: the jungle, desert, sea, cities, and mountains. Among them, the region's main background color and its proportion as shown in Table 2.

Table 2. The main color distribution under the different terrain

\begin{tabular}{lllllll}
\hline Terrain & green & yellow & gray & brown & white & blue \\
\hline Jungle area & $80 \%$ & 0 & 0 & $20 \%$ & 0 & 0 \\
Desert region & 0 & $80 \%$ & 0 & $20 \%$ & 0 & 0 \\
City Region & $40 \%$ & 0 & $60 \%$ & 0 & 0 & 0 \\
Marine region & 0 & 0 & 0 & 0 & $40 \%$ & $60 \%$ \\
Mountainous region & $50 \%$ & $50 \%$ & 0 & 0 & 0 & 0 \\
\hline
\end{tabular}

\subsection{The Analysis and Solving of the Question 2}

\subsubsection{Model I: The Color Difference Comparative Model Based on the Color Wheel Parameters}

\subsubsection{The Background of the Model $I$}

Color, just like music, is a kind of feeling. Music depends on scales to maintain order and form a system. In the same way, the color scales of the three attributes, which can use them to keep order among various color and form an easy and convenient color system. All the color can be arranged in a ring. 
The phenomenon that when discretional two color or various color collocation are together, the different show in the color ring form a flagrant contrast, is called color ring contrast(Chen, 2014).

Adjacent ring in the color wheel from $\frac{\pi}{12}$ to $\frac{\pi}{6}$; A similar ring contrast within $\frac{\pi}{3}$; Difference in ring contrast within $\frac{\pi}{2}$; Contrast is less than $\frac{2 \pi}{3}$; Complementary color contrast within $\pi$.

\subsubsection{The Analysis of the Model $I$}

From the color of camouflage in the big environment of hidden degree, color difference analysis is a good quantitative indicator, through the background color and camouflage color between the color difference degrees, it can reflect the degree of camouflage to hide. That is, the two hue difference more, that the better the effect of camouflage to hide.

\subsubsection{The Establishment of the Model $I$}

\subsection{The assumption of the Model $I$}

a) The proportion of camouflage in the three colors is equal

b) To facilitate the radian system comparison, assumption that the color different between the interval of two color rings and the different color in the same color ring is equal.

The radius of the color ring is $\frac{5}{9} \pi$, the distant between two color rings is $\frac{\pi}{18}$. Each color has the CMYK code; the center of the each color pattern represents this kind of color.

Based on center as the origin, a two-dimensional Cartesian coordinate system is created as shown in the figure below.

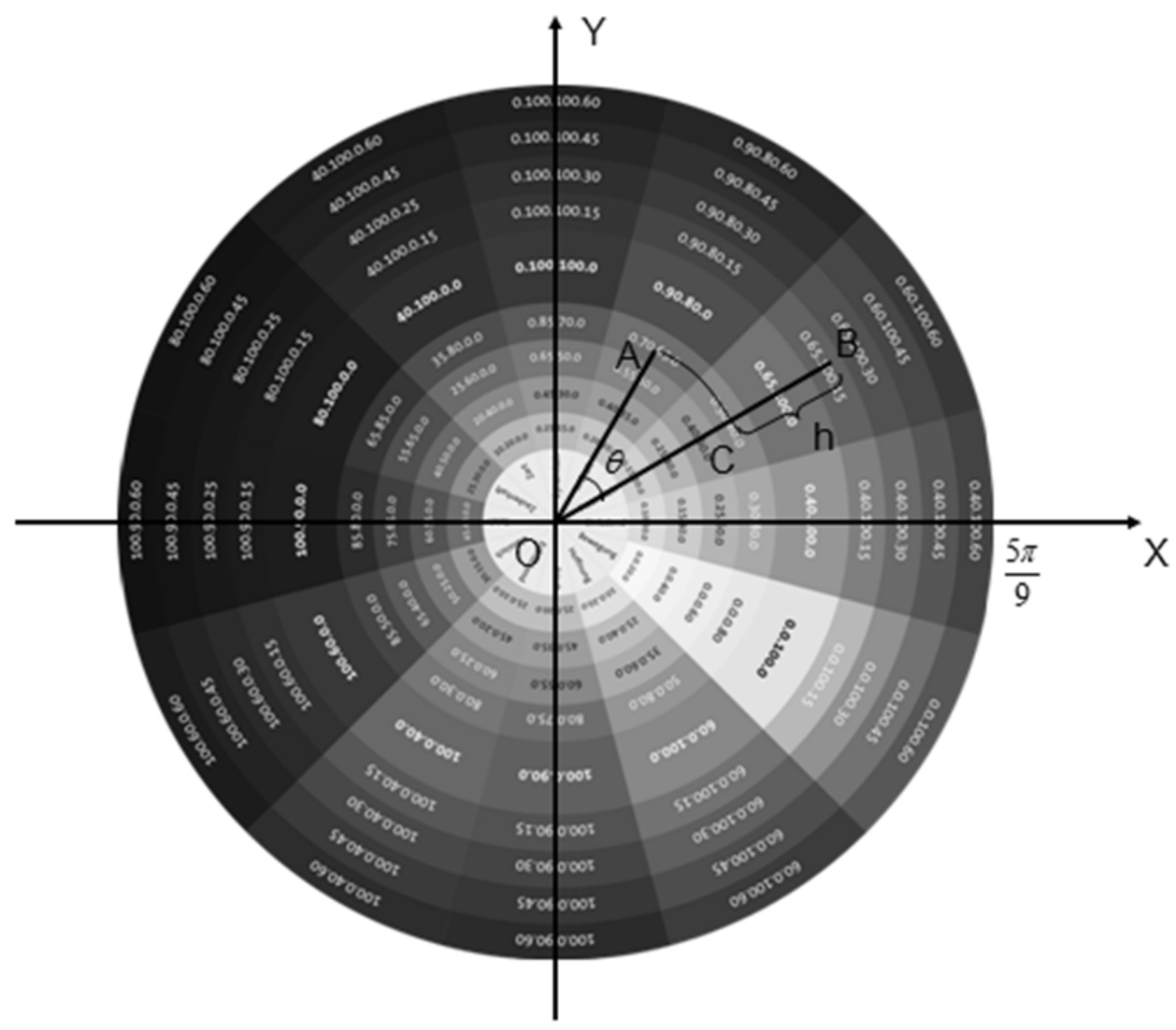

Figue 1. The color ring under the Cartesian coordinate system 
c) The Further Analysis of the Model

We pick up two colors named $\mathrm{A}$ and $\mathrm{B}$ arbitrarily, $\mathrm{AO}, \mathrm{BO}$ is underlined and the cute angle of the $\angle A O B$ is named as $\theta$ in the Figure 1. Point $\mathrm{C}$ is in the same color ring as point $\mathrm{A}$ and it belongs to the same Sector as point B. the distant between CB is named as $h$. So the color different is as follow (Han, Wu, Qiu, \& Ren, 2009).

$$
A_{i j}=\theta+h
$$

$i, j$ is represent two CMYK code separately

Based on the MATLAB programming and calculating, the result is shown in the Table 3 below.

Table 3. The result

\begin{tabular}{lccccc}
\hline & Jungle area & Desert region & Mountainous region & Marine region & City Region \\
\hline Patterns 1 & 3.454 & 2.0584 & 3.8203 & 4.5356 & 6.2102 \\
Patterns 2 & 3.7331 & 1.0816 & 3.6808 & 5.3729 & 6.6638 \\
Patterns 3 & 4.1867 & 4.0471 & 5.5822 & 4.2216 & 5.7916 \\
Patterns 4 & 5.6869 & 2.0584 & 3.9773 & 5.1287 & 7.5709 \\
Patterns 5 & 6.1404 & 5.024 & 5.8788 & 3.9773 & 6.6987 \\
Patterns 6 & 5.024 & 4.0471 & 5.7392 & 4.8147 & 7.1522 \\
Patterns 7 & 4.9542 & 1.9189 & 2.9132 & 4.0122 & 6.1404 \\
Patterns 8 & 4.8147 & 2.512 & 3.5936 & 2.8609 & 5.2682 \\
Patterns 9 & 3.6982 & 3.9076 & 5.9311 & 3.4889 & 5.7218 \\
Patterns 10 & 5.652 & 4.0471 & 7.065 & 3.454 & 6.6289 \\
\hline
\end{tabular}

The result demonstrate that when other conditions are fixed, the smaller values are, the better hidden performance will be.

\subsubsection{Model II-the Image Complexity Analysis Model Under the General Collection}

1) Proposition of Model $I I$

Complexity of a camouflage pattern is a description of inherent complexity of an image; it can reflect the diversity of the combination of internal colors and shapes. Not only can we conduct and grasp the process and analysis of camouflage patterns better, but also we can analyze the complexity degrees between camouflage patterns and terrain patterns comparatively by describing the complex degree of camouflage patterns quantitatively. As a result, we can acquire the optimal design effect of camouflage pattern.

\section{2) Analysis of Model $I I$}

We introduce the image complexity analysis model based on the general collection to research for the complex degree of camouflage patterns. The general collection needs to identify which two of elements are different in a collection, and it also have to know the number of element. Therefore, the general collection is capable of distinguishing individuals with different nature in its system, and it can also calculate the number of individuals with the same nature.

The model takes advantage of MATLAB and we can get the grey statistics histogram of the primitive patterns aiming at the characteristics of patterns. In addition, we can describe the complexity of patterns based on the degree of grey level of images, the frequency of each grey level, the style and distribution of patterns comprehensively (Hou, Yu, \& Chen, 2013).

When it comes to patterns, the calculation of complexity degree is directly related to the grey statistics histogram. What's more, we can obtain the complex degree of corresponding camouflage pattern because of the grey statistics histogram which demonstrates the frequency of each grey level taken in to the image complexity analysis model

3) The establishment and solution of the model

(1). the formula of complexity of the internal condition in general collection is: 


$$
C=-\sum_{i=1}^{K} n_{i} \cdot \log \left(n_{i} / N\right)
$$

In the formula, $C$ represents the complexity of pattern; $k$ represents the number of colors in patterns; $N$ means the numbers of grey level of patterns; $n_{i}$ represents the number of the $i$ kind of grey level.

(2). the solution to the complex degree of ten kinds of camouflage pattern The complexity of camouflage image is $C_{i}$, the complexity of terrain image is $C_{m}$, so $h=\left|C_{i}-C_{m}\right|$

We can acquire the complexity of camouflage image and terrain image and the absolute complex differences of images based on the set of ten kinds of camouflage patterns and terrains, combining with the image complexity analysis model. The consequence is shown in the table as below:

Table 4. the result

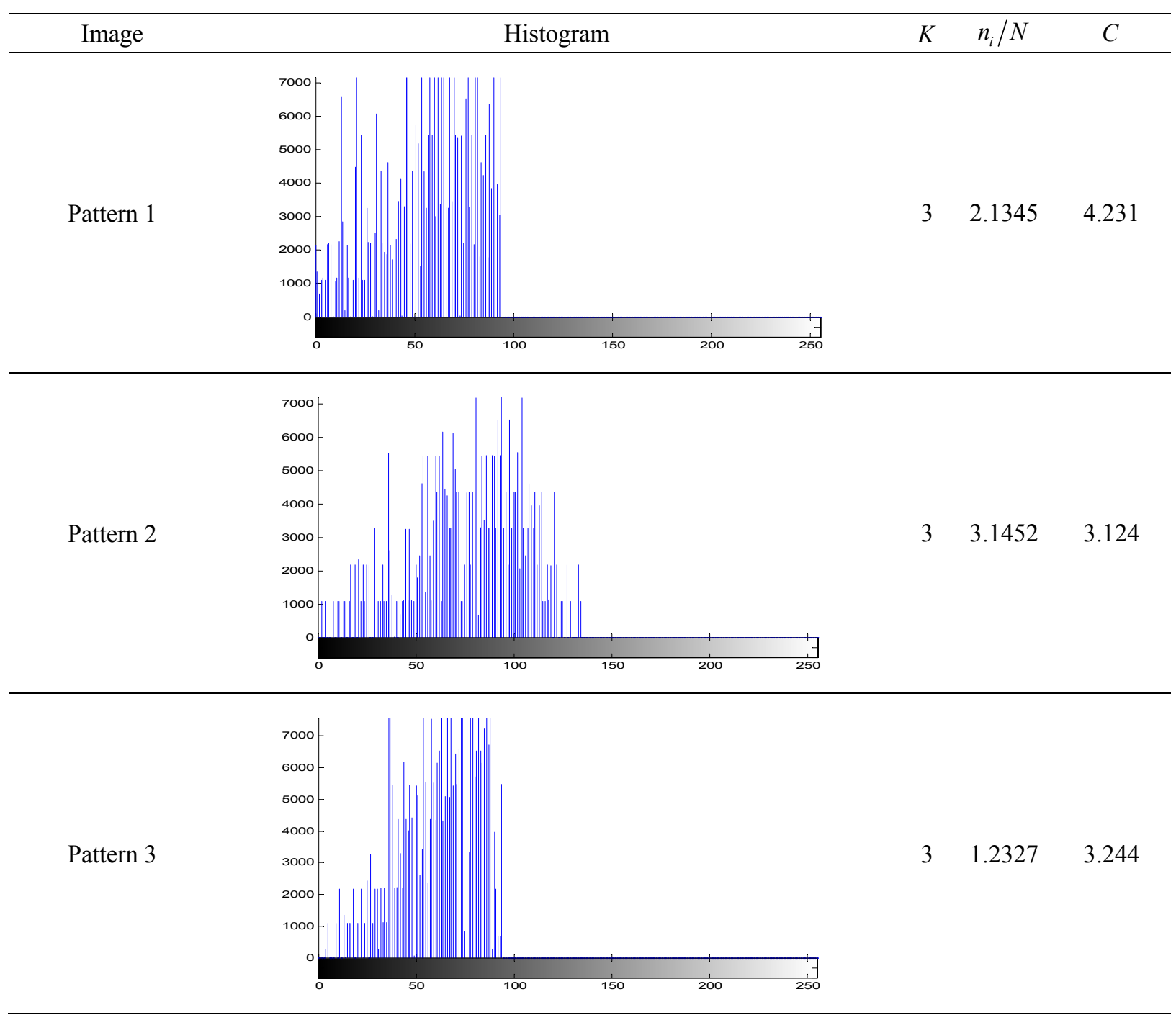




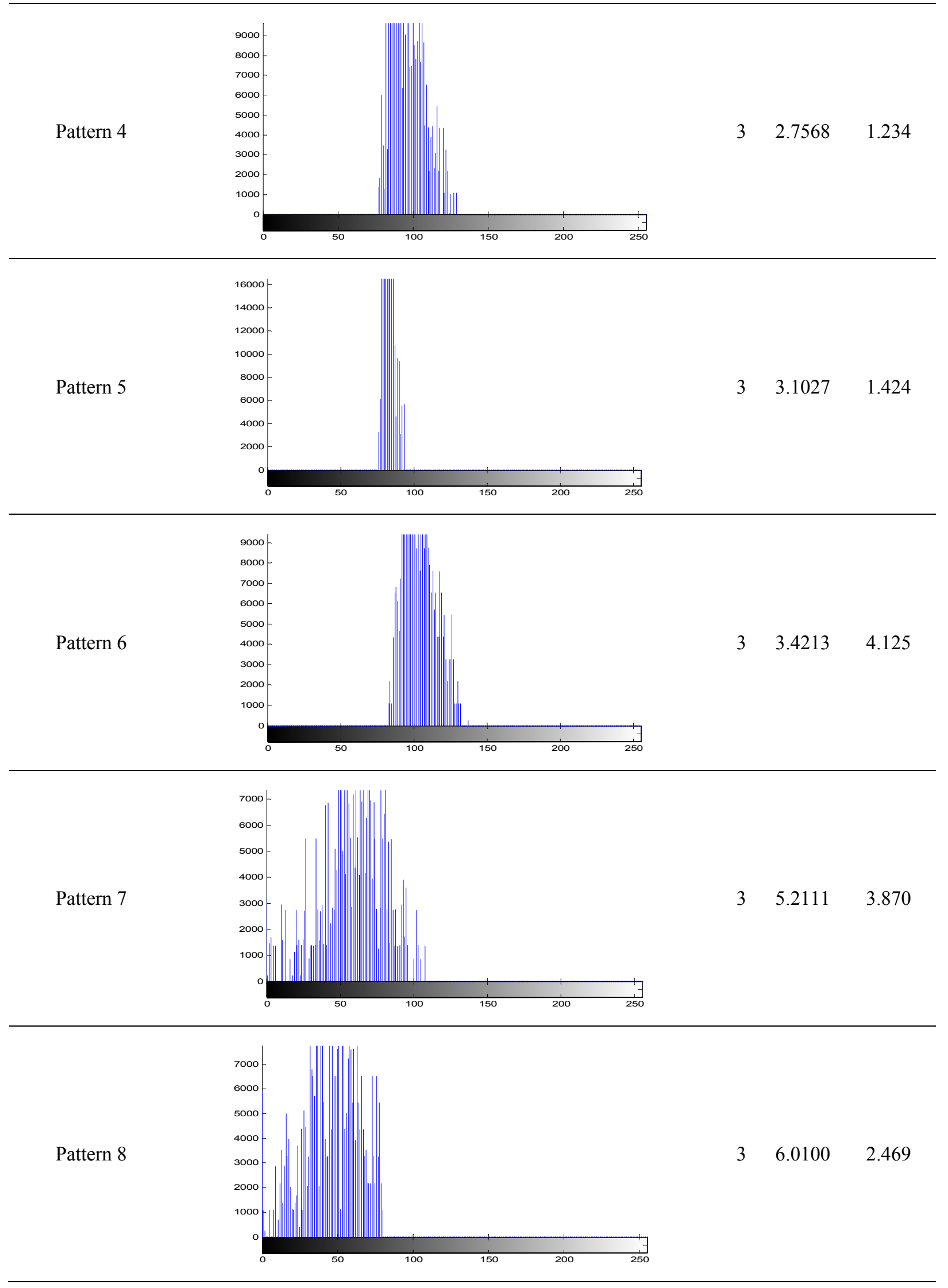




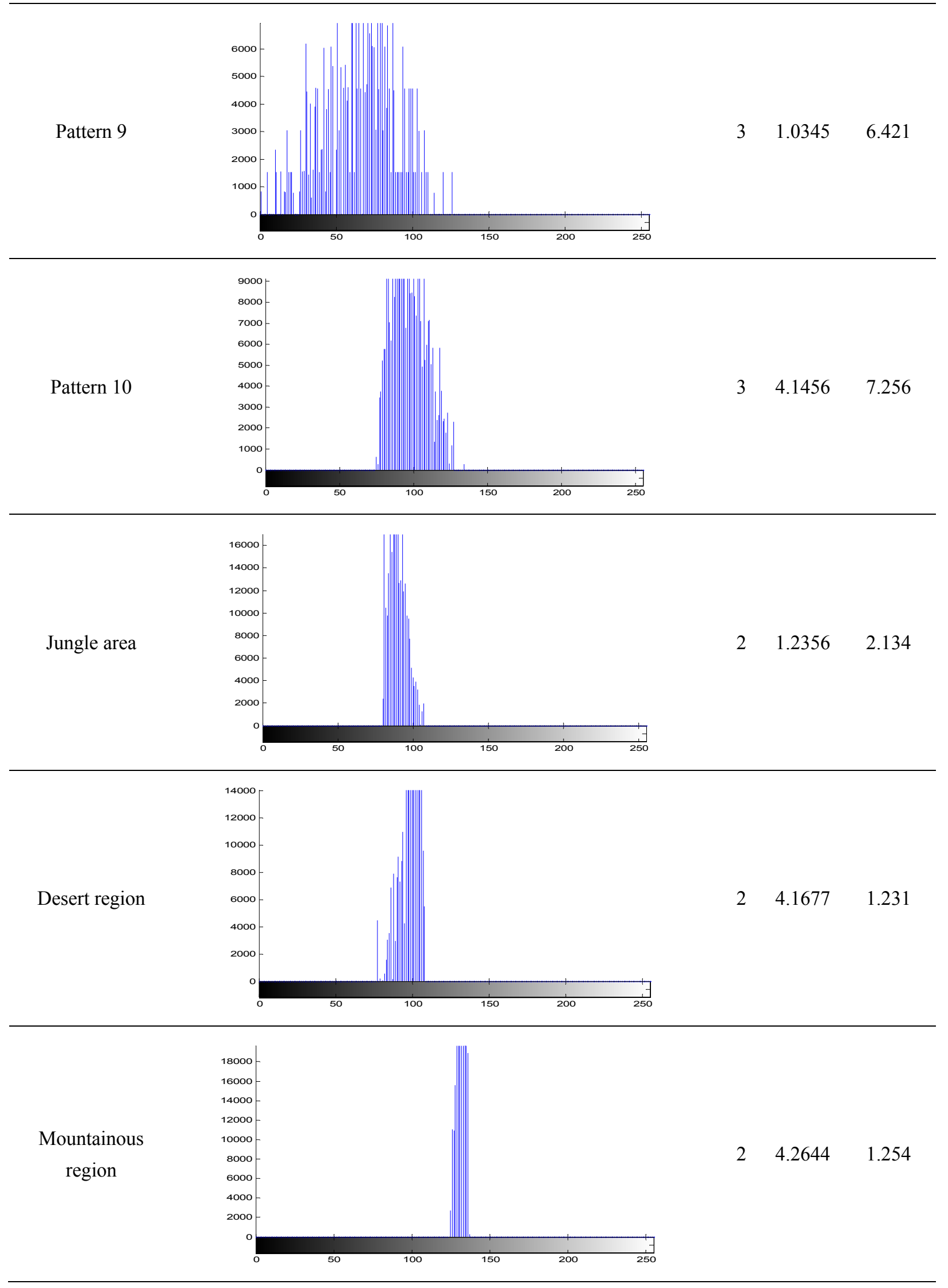




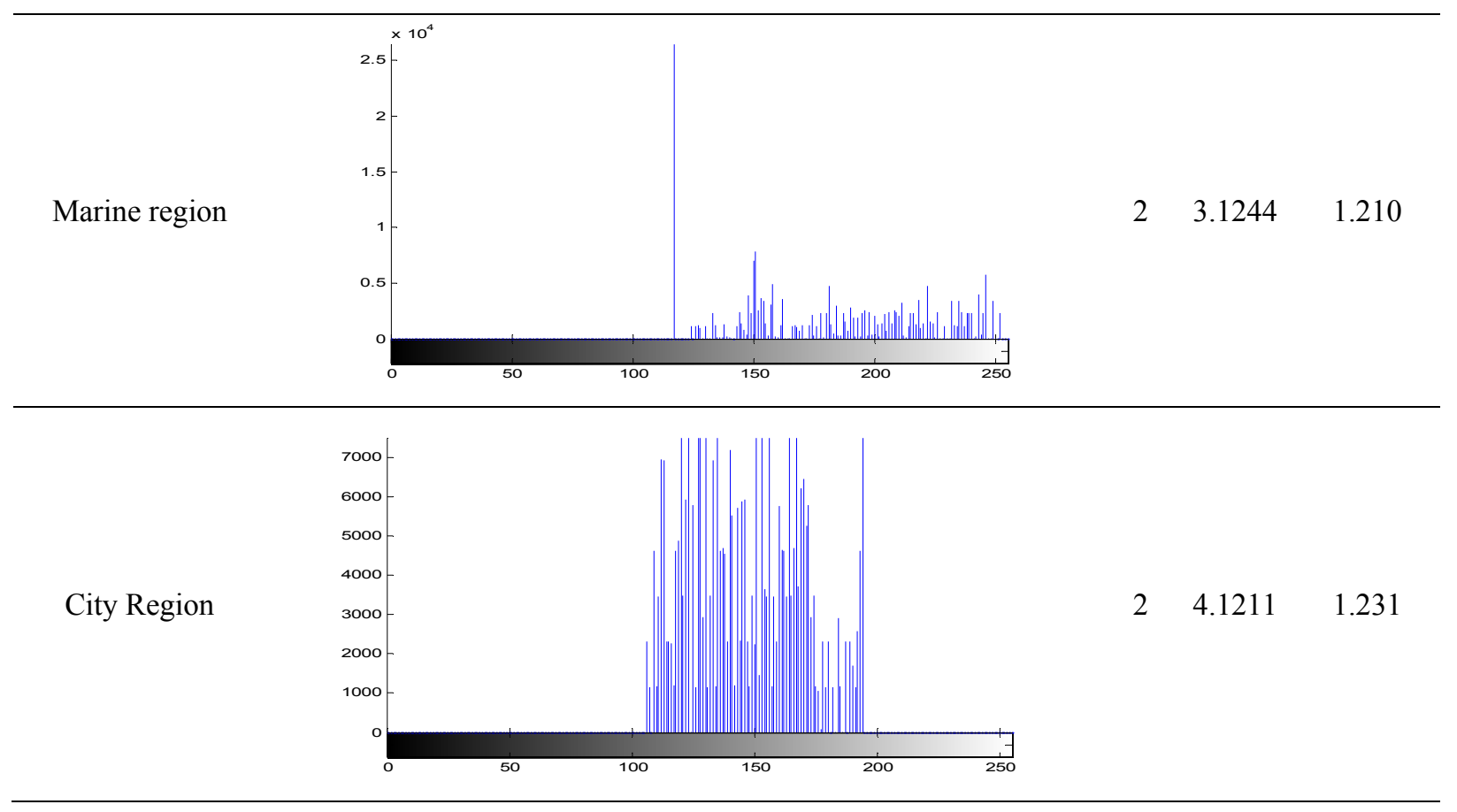

Table 5. Complex absolute difference value

\begin{tabular}{cccccc}
\hline & Jungle area & Desert region & Mountainous region & Marine region & City Region \\
\hline Pattern 1 & 2.0970 & 3.0003 & 2.9773 & 3.0214 & 3.0000 \\
Pattern 2 & 0.9893 & 1.8926 & 1.8696 & 1.9137 & 1.8923 \\
Pattern 3 & 1.1100 & 2.0133 & 1.9903 & 2.0344 & 2.0130 \\
Pattern 4 & 0.9002 & 0.0031 & 0.0199 & 0.0242 & 0.0028 \\
Pattern 5 & 0.7100 & 0.1933 & 0.1703 & 0.2144 & 0.1930 \\
Pattern 6 & 1.9903 & 2.8936 & 2.8706 & 2.9147 & 2.8933 \\
Pattern 7 & 1.7351 & 2.6384 & 2.6154 & 2.6595 & 2.6381 \\
Pattern 8 & 0.3345 & 1.2378 & 1.2148 & 1.2589 & 1.2375 \\
Pattern 9 & 4.2871 & 5.1904 & 5.1674 & 5.2115 & 5.1901 \\
Pattern 10 & 5.1220 & 6.0253 & 6.0023 & 6.0464 & 6.0250 \\
\hline
\end{tabular}

Finally, we can get the minimum absolute complex differences of images between different terrains (such as jungle, desert region, mountain, marine region and city) and corresponding camouflage pattern. The consequence are $(0.3345,0.0031,0.0199,0.0242,0.0028)$. So the pattern 8 is much more suitable for jungle areas, and the pattern 4 prefers to desert, mountain, and city areas.

5.2.3 Model III — the Ability of Hiding Model Based on the Brightness of the Color Formula

1). The model put forward

Due to the different color camouflage, hiding effect on its brightness camouflage also have a great impact, while the low brightness account for a large advantage in military camouflage, it could well be the operational side hidden and not to be found. By introducing the brightness index and brightness index percentage, we can camouflage hiding capacity quantitative analysis.

2). The analysis of the problem

Firstly, according to an analysis of the actual color of each terrain and distribution ratios, we propose the hypothesis color scale and combined in different combinations of model $I$, then CMYK format is converted to RGB format. Secondly, we passed RGB color brightness relationship; calculate the corresponding intensity of the 
color. Finally, according to the intensity at different terrain, we design each color brightness corresponding to the combination were compared with the terrain, based on its contrast with the closeness of a value system. We judge each color combination integrated brightness of the hidden strength of the effect.

3). The establishment of the model

We assume that the same proportion of camouflage in each color, brightness of the color combinations may be taken simple arithmetic mean. Because the proportion of different colors for each of the terrain, it will calculate the corresponding color brightness weighted arithmetic (Hu, Zhu, Wang, \& Lu, 2007).

The relationship between Brightness and RGB code is as follows

$$
Y=0.299 R+0.587 G+0.114 B
$$

We compare camouflage color brightness $Y_{1}$ and color brightness terrain $Y_{2}$. When the two values are similar, the ratio has close to 1 , so we can make a equation as follow

$$
\gamma=\left|\frac{Y_{1}}{Y_{2}}-1\right|
$$

When the percentage of $\gamma$ is larger, the gap between camouflage color brightness and terrain color is bigger.

4). The further analysis of the model

According to each color of CMYK corresponding code, first of all, we use Photoshop software is converted to RGB code. Then we calculate the brightness of terrain color and camouflage pattern based on the equation (1).the results are as follows.

Table 6. Terrain color corresponding RGB and luminance

\begin{tabular}{lllll}
\hline & $\mathrm{R}$ & $\mathrm{G}$ & $\mathrm{B}$ & brightness \\
\hline brown & 148 & 83 & 5 & 93.543 \\
olive green & 53 & 101 & 7 & 75.932 \\
yellow & 194 & 135 & 0 & 137.251 \\
blue & 32 & 90 & 167 & 81.436 \\
black & 0 & 0 & 0 & 0 \\
\hline
\end{tabular}

Table 7. Camouflage colors corresponding RGB and luminance

\begin{tabular}{llllll}
\hline \multirow{4}{*}{ green } & Jungle area & 0 & 125 & 66 & 80.899 \\
& Mountainous region & 80 & 166 & 37 & 125.58 \\
& City Region & 0 & 160 & 107 & 106.118 \\
\multirow{2}{*}{ brown } & Jungle area & 188 & 93 & 0 & 110.803 \\
& Desert region & 129 & 66 & 0 & 77.313 \\
gray & City Region & 194 & 194 & 194 & 194 \\
blue & Marine region & 0 & 166 & 173 & 117.164 \\
white & Marine region & 255 & 255 & 255 & 255 \\
\multirow{2}{*}{ yellow } & Desert region & 151 & 109 & 0 & 109.132 \\
& Mountainous region & 194 & 135 & 0 & 137.251 \\
\hline
\end{tabular}

Secondly, we use Excel software to calculate the combination of colors for each color brightness percentage number in each environment, as shown in Table 8. 
Table 8. the result

\begin{tabular}{lccccc}
\hline & Jungle area & Desert region & Mountainous region & Marine region & City Region \\
\hline Pattern 1 & 0.3498 & 0.4503 & 0.5701 & 0.6476 & 0.6444 \\
Pattern 2 & 0.1145 & 0.2514 & 0.4146 & 0.5201 & 0.5157 \\
Pattern 3 & 0.3287 & 0.4324 & 0.5562 & 0.6361 & 0.6328 \\
Pattern 4 & 0.1768 & 0.0051 & 0.2220 & 0.3622 & 0.3564 \\
Pattern 5 & 0.0373 & 0.1862 & 0.3636 & 0.4782 & 0.4735 \\
Pattern 6 & 0.1979 & 0.0127 & 0.2080 & 0.3507 & 0.3448 \\
Pattern 7 & 0.1821 & 0.3085 & 0.4593 & 0.5567 & 0.5526 \\
Pattern 8 & 0.3962 & 0.4896 & 0.6008 & 0.6728 & 0.6698 \\
Pattern 9 & 0.1610 & 0.2907 & 0.4453 & 0.5453 & 0.5411 \\
Pattern 10 & 0.1304 & 0.0444 & 0.2527 & 0.3874 & 0.3818 \\
\hline
\end{tabular}

Finally, according to the table three, the minimum brightness in different environments (jungle, desert, mountains, oceans, cities) corresponds to the percentage of each Patterns camouflage color number $(0.0373,0.0051,0.2080$, $0.3507,0.3448$ ). Therefore, Patterns color table 5 jungle environment suitable combination class, Patterns four categories for desert environment, Patterns 6 for the mountains, ocean and city class environment (Hua, Yang, Liu, \& Ma, 2013).

\subsubsection{Model $I V$-Wavelength Correlation Coefficient Model based on Spectroscopy}

1). The establishment of the model

In our nature, each kind of visible light has its corresponding wavelength and different color has different wavelength. We can investigate wavelength of each color in any given image, and compare the wavelength of camouflage patterns and that of basic terrains based on the ten kinds of camouflage patterns and five kinds of terrains acquired in question 2 . Therefore, we can get the correlation coefficient between them, and analyze the low-visibility effect of different kinds of camouflage patterns in five terrains.

2). The establishment of the model

In the table, we can find out the wavelength of 8 representative kinds of colors in each pattern, and calculate the correlation coefficient $r$ between camouflage patterns and terrains. The more the absolute correlation coefficient is closer to 1, the better the low-visibility effect will be in any given terrain (Wang, Yan, \& Jiao, 2013).

Table 9. The basic terrain wavelength table

\begin{tabular}{llllll}
\hline & Jungle area & Desert region & Mountainous region & Marine region & City Region \\
\hline 1 & 570 & 590 & 530 & 475 & 530 \\
2 & 595 & 587 & 531 & 450 & 465 \\
3 & 605 & 587 & 567 & 462 & 527 \\
4 & 571 & 591 & 570 & 472 & 521 \\
5 & 531 & 586 & 590 & 471 & 565 \\
6 & 578 & 610 & 582 & 480 & 450 \\
7 & 593 & 608 & 600 & 452 & 463 \\
8 & 561 & 589 & 592 & 463 & 562 \\
\hline
\end{tabular}

Table 10. The camouflage patterns wavelength table

\begin{tabular}{|c|c|c|c|c|c|c|c|c|c|c|}
\hline & Pattern 1 & Pattern 2 & Pattern 3 & Pattern 4 & Pattern 5 & Pattern 6 & Pattern 7 & Pattern 8 & Pattern 9 & Pattern 10 \\
\hline 1 & 615 & 593 & 473 & 513 & 565 & 600 & 562 & 379 & 480 & 563 \\
\hline 2 & 660 & 592 & 572 & 595 & 601 & 475 & 591 & 575 & 590 & 607 \\
\hline 3 & 610 & 583 & 608 & 581 & 575 & 474 & 555 & 530 & 470 & 567 \\
\hline 4 & 595 & 592 & 470 & 567 & 480 & 450 & 475 & 391 & 573 & 474 \\
\hline 5 & 614 & 610 & 592 & 582 & 580 & 592 & 483 & 595 & 593 & 480 \\
\hline 6 & 595 & 575 & 407 & 575 & 587 & 605 & 491 & 582 & 470 & 581 \\
\hline 7 & 587 & 591 & 595 & 594 & 595 & 472 & 560 & 574 & 463 & 595 \\
\hline 8 & 610 & 607 & 470 & 610 & 530 & 583 & 532 & 470 & 569 & 582 \\
\hline
\end{tabular}


We design that each column of number in matrix in table 1 is $A_{n}$, each column of number in matrix in Table 2 is $B_{m}, \quad(n=m=1,2,3,4,5,6,7,8), x, y$ represent the data in $A_{n}, B_{m}$ respectively. So, the formula of wavelength correlation coefficient between certain kind of camouflage pattern and the given terrain is shown as below:

$$
r\left(A_{n}, B_{m}\right)=\frac{\sum_{i=1}^{n}\left(x_{i}-\bar{x}\right)\left(y_{i}-\bar{y}\right)}{\sqrt{\sum_{i=1}^{n}\left(x_{i}-\bar{x}\right)^{2} \cdot \sum_{i=1}^{m}\left(y_{i}-\bar{y}\right)^{2}}}
$$

3). Specific Solving

Table 11. correlation coefficient table

\begin{tabular}{cccccc}
\hline Correlation coefficient & Jungle area & Desert region & Mountainous region & Marine region & City Region \\
\hline Pattern 1 & 0.4560 & 0.7438 & 0.3000 & 0.2892 & 0.7909 \\
Pattern 2 & 0.7234 & 0.5686 & 0.2051 & 0.1522 & 0.7450 \\
Pattern 3 & 0.2114 & 0.3281 & 0.0565 & 0.6945 & 0.0934 \\
Pattern 4 & 0.0929 & 0.0438 & 0.5466 & 0.6221 & 0.0623 \\
Pattern 5 & 0.2727 & 0.2748 & 0.0970 & 0.3475 & 0.4761 \\
Pattern 6 & 0.6333 & 0.0789 & 0.0832 & 0.6304 & 0.2949 \\
Pattern 7 & 0.6378 & 0.1357 & 0.5176 & 0.7132 & 0.2807 \\
Pattern 8 & 0.0257 & 0.2620 & 0.4344 & 0.1888 & 0.3765 \\
Pattern 9 & 0.5343 & 0.6249 & 0.0679 & 0.1392 & 0.4224 \\
Pattern 10 & 0.6508 & 0.3492 & 0.1861 & 0.5062 & 0.5601 \\
\hline
\end{tabular}

The table illustrates that the maximum wavelength correlation coefficient of each corresponding camouflage pattern under different terrains (such as jungle, desert region, mountain, marine region and city) are $(0.7234$, $0.7438,0.5466,0.7132,0.7909)$. So the color of pattern 2 is much more suitable for jungle areas. However, the pattern 1, 4, 7 are suitable for desert, city area, and marine area respectively (Xiao, 2006).

\subsubsection{Model $V$-A Significant Degree of Camouflage Model}

1). The set of the model

We can know from the Visual imaging principle of human eyes that adjacent colors are prone to be mixed when we observe colors, and it is the reason for low-visibility effect. So it is necessary for us to find appropriate "Significant degree" to acquire the optimal low-visibility effect. Also, we can analyze the capability of low-efficiency of camouflage patterns quantitatively by bring in the index of significant degree.

2). Analysis of question

To begin with, we analyze the real situation based on the relationship between each terrain and corresponding observe distance under the hypothesis that the corresponding observation distance of jungle, desert area, mountain, marine area and city are $500 \mathrm{~m} 、 1000 \mathrm{~m} 、 800 \mathrm{~m} 、 12000 \mathrm{~m} 、 300 \mathrm{~m}$. Secondly, according to model and model II, the color difference and brightness of camouflage patterns also have an impact on the size of significant degree. So, the significant degree and the color difference and brightness have notable positive correlation and the degree descends with the increase color difference and brightness. Finally, we can calculate the level of significant degree of each kind of color combination via EXCEL.

3). The establishment of the model

The Angle indexing of the human eye is about 0.017 degrees based on the human visible principle (Yang, 2011). If the angle of human eyes is less than 0.017 degree in certain situation, the pattern would be fuzzy and difficult to be recognized. We assume that the significant degree is $a \times a$, and the observation distance is $\mathrm{D}$, color difference is $y_{i}$, brightness is $y_{i}^{\prime}$, and the angle is $\alpha$. So, the formula of the maximum level of significant degree is shown as below:

$$
a_{i}=D y_{i} y_{i}^{\prime} \tan \alpha \quad(i=1,2, \cdots, 10)
$$


4). The concrete solution to the model

We show the level of significant degree of different terrains corresponding to different colors of patterns as below:

Table 12. Different environment corresponding to different styles of significant degree of color

\begin{tabular}{llllll}
\hline & Jungle area & Desert region & Mountainous region & Marine region & City Region \\
\hline Pattern 1 & 0.1792 & 0.275 & 0.517 & 10.4577 & 0.3562 \\
Pattern 2 & 0.0634 & 0.0807 & 0.3622 & 9.9493 & 0.3059 \\
Pattern 3 & 0.2042 & 0.5192 & 0.7370 & 9.5609 & 0.3262 \\
Pattern 4 & 0.1492 & 0.0031 & 0.2096 & 6.6138 & 0.2402 \\
Pattern 5 & 0.0340 & 0.2776 & 0.5074 & 6.7717 & 0.2823 \\
Pattern 6 & 0.1475 & 0.0152 & 0.2834 & 6.0117 & 0.2195 \\
Pattern 7 & 0.1338 & 0.1756 & 0.3176 & 7.9525 & 0.3020 \\
Pattern 8 & 0.283 & 0.3649 & 0.5125 & 6.8531 & 0.3141 \\
Pattern 9 & 0.0883 & 0.3370 & 0.6269 & 6.7736 & 0.2756 \\
Pattern 10 & 0.1093 & 0.0533 & 0.4238 & 4.7641 & 0.2253 \\
\hline
\end{tabular}

The table shows that the minimum significant level of corresponding each camouflage pattern under different terrains (such as jungle, desert region, mountain, marine region and city) are $(0.0340,0.0031,0.2096,4.7641$, 0.2195 ) respectively. So, we can easy to know that pattern5, 4, 10, 6 are suitable for jungle, desert and mountain, marine area, and city area respectively.

\subsection{The analysis and Solving of the Question 3}

\subsubsection{The Problem Put Forward}

In the determination of the camouflage patterns, we integrated judge its optimal concealment performance only by single index is not accurate. Therefore, the five model parameters we choose three of the calculated, comprehensive evaluating best under different conditions of camouflage patterns of sorting, and we get to the comprehensive evaluation of $\mathrm{F}$ value as the basis, provides the help for the whole road optimal pattern design.

\subsubsection{Analysis and Problem Solving}

Model VI-Hidden effect comprehensive evaluation model based on the Fuzzy Comprehensive Evaluation Method

(1) The ideal solution:

$$
\begin{gathered}
u=\left(u_{1}^{0}, u_{2}^{0}, u_{3}^{0}, u_{4}^{0}, u_{5}^{0}\right) \\
u_{i}^{0}=\left\{\begin{array}{lc}
\max \left\{a_{i j}\right\} & \text { when } a_{i j} \text { is benifit indexes } \\
\min \left\{a_{i j}\right\} & \text { when } a_{i j} \text { is } \cos \text { tindexes }
\end{array}\right.
\end{gathered}
$$

(2) Create a relative deviation of fuzzy matrix $R$ :

$$
\begin{gathered}
\underset{\sim}{R}=\left(\begin{array}{cccc}
r_{11} & r_{12} & \cdots & r_{15} \\
r_{21} & r_{22} & \cdots & r_{25} \\
\vdots & \vdots & & \vdots \\
r_{41} & r_{42} & \cdots & r_{46}
\end{array}\right) \\
r_{i j}=\frac{\left|a_{i j}-u_{i}^{0}\right|}{\max \left\{a_{i j}\right\}-\min \left\{a_{i j}\right\}} .
\end{gathered}
$$

(3) We set up the index weight of evaluation $\omega_{i}(i=1,2, \cdots, 5)$, based on the relative deviation of fuzzy matrix $R$ According to the variation coefficient method: 


$$
v_{j}=\frac{s_{j}}{\overline{x_{j}}}, \quad \omega_{j}=\frac{v_{j}}{\sum_{j=1}^{5} v_{j}}
$$

Comprehensive evaluation model

$$
F_{i}=\sum_{j=1}^{5} \omega_{i} r_{i j}
$$

When $F_{t}<F_{s}$, means that the scheme $t$ is better than scheme $s$.

(4) Detailed numerical calculation

We use MATLAB to the F value is as follows:

Table 13. the result

\begin{tabular}{cccccc}
\hline F value & Jungle area & Desert region & Mountainous region & Marine region & City Region \\
\hline Pattern 1 & 0.4892 & 0.4639 & 0.5149 & 0.6921 & 0.4300 \\
Pattern 2 & 0.1163 & 0.2653 & 0.4988 & 0.6603 & 0.3046 \\
Pattern 3 & 0.5318 & 0.7132 & 0.5967 & 0.3995 & 0.6332 \\
Pattern 4 & 0.4678 & 0.2318 & 0.1759 & 0.1748 & 0.3937 \\
Pattern 5 & 0.2415 & 0.4708 & 0.4801 & 0.3195 & 0.2754 \\
Pattern 6 & 0.3572 & 0.3999 & 0.6278 & 0.3281 & 0.4626 \\
Pattern 7 & 0.3179 & 0.5127 & 0.353 & 0.3589 & 0.5571 \\
Pattern 8 & 0.6587 & 0.6098 & 0.3485 & 0.4924 & 0.4500 \\
Pattern 9 & 0.4318 & 0.5951 & 0.7518 & 0.7470 & 0.6390 \\
Pattern 10 & 0.5000 & 0.4703 & 0.7390 & 0.5234 & 0.5663 \\
\hline
\end{tabular}

We sort the data from small to large, top-ranking priority to choose from. The results are as follows

Tab 14. the result

\begin{tabular}{llllll}
\hline & Jungle area & Desert region & Mountainous region & Marine region & City Region \\
\hline The first choice & Pattern 2 & Pattern 4 & Pattern 4 & Pattern 4 & Pattern 5 \\
The second choice & Pattern 5 & Pattern 2 & Pattern 8 & Pattern 5 & Pattern 2 \\
The third choice & Pattern 7 & Pattern 6 & Pattern 7 & Pattern 6 & Pattern 4 \\
The fourth option & Pattern 6 & Pattern 1 & Pattern 5 & Pattern 7 & Pattern 1 \\
The fifth choice & Pattern 9 & Pattern 10 & Pattern 2 & Pattern 3 & Pattern 8 \\
The sixth choice & Pattern 4 & Pattern 5 & Pattern 1 & Pattern 8 & Pattern 6 \\
The seventh choice & Pattern 1 & Pattern 7 & Pattern 3 & Pattern 10 & Pattern 7 \\
The eighth choice & Pattern 10 & Pattern 9 & Pattern 6 & Pattern 2 & Pattern 10 \\
The ninth choice & Pattern 3 & Pattern 8 & Pattern 10 & Pattern 1 & Pattern 3 \\
The tenth choice & Pattern 8 & Pattern 3 & Pattern 9 & Pattern 9 & Pattern 9 \\
\hline
\end{tabular}

According to the table 14, In a jungle location, Patterns 2 camouflage hiding effect is best, the Patterns of 5 hidden effect is the second good, the Patterns of 8 camouflage hiding effect is the worst. 


\subsection{The Analysis and Solving of the Question 4}

\subsubsection{The problem Put Forward}

We just solved in one single terrain on the optimal combination of camouflage patterns, but in real life, a kind of camouflage patterns could not only be applied to a terrain. Camouflage patterns will be used in a variety of terrain. So, for some kind of camouflage pattern, through the combination of subjective and objective determine its use frequency in different terrain is very necessary, therefore, we through the determination of frequency, solving problems as a result, calculate and design the camouflage which is suitable for all the terrain.

\subsubsection{Analysis and Problem Solving}

The usage of the Analytic hierarchy process is as follows

1). Establish class hierarchy:

The target layer A: Camouflage patterns on the use of frequency in different terrain.

Rule layer B: Camouflage patterns

Scheme layer C: Different terrain types

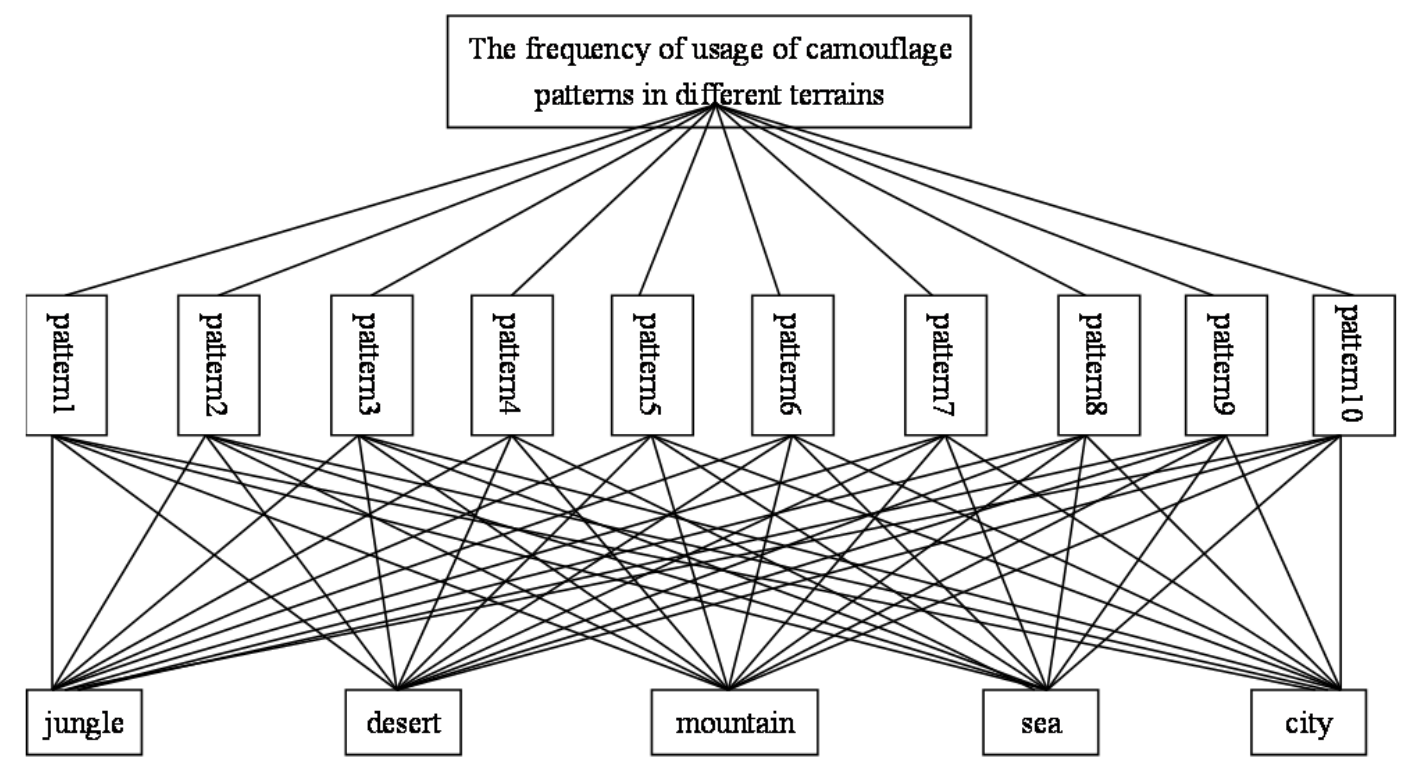

Figure 3. Class time structure

Mostly adopt the method is to fill out the person (experts) repeatedly asked in view of the judgment matrix criterion, in which two elements which two more important, how much important, the degree of importance to press 1-9 assignment importance scale value (see chart below) (Yuan, 2008).

Table 15. Judgment matrix

\begin{tabular}{c}
\hline Meaning \\
\hline 1 \\
3 \\
5 \\
7 \\
9 \\
$2,6,8$ \\
The former is slightly more important than the latter \\
The former is more important than the latter \\
The former is strongly important than the latter \\
The former is extremely important than the latter \\
If the ratio of the important of the element i and the element $\mathrm{j}$ is $a_{i j}$, the important of \\
the element $\mathrm{j}$ and the element $\mathrm{i}$ is $a_{i j}=1 / a_{j i}$
\end{tabular}


Judgment matrix $\mathrm{A}_{i j}=\left(a_{i j}\right)_{n \times n}$ meet:

$$
\begin{aligned}
& \text { (1) } a_{i j}>0 ; \\
& \text { (2) } a_{i j}=1 / a_{j i} \quad(i, j=12234) \text {; } \\
& \text { (3) } a_{i i}=1 .
\end{aligned}
$$

We fill in after the judgment matrix as follows on the basis of expert analysis and opinion: (The target layer)

$$
A=\left(\begin{array}{cccccccccc}
1 & 1 / 2 & 1 / 3 & 2 & 3 & 1 / 4 & 2 & 4 & 5 & 1 / 5 \\
2 & 1 & 1 / 7 & 6 & 1 / 4 & 3 & 3 & 1 / 2 & 4 & 2 \\
3 & 7 & 1 & 1 / 9 & 1 / 2 & 4 & 3 & 1 / 5 & 5 & 3 \\
1 / 2 & 1 / 6 & 9 & 1 & 1 / 3 & 2 & 7 & 1 / 2 & 2 & 5 \\
1 / 3 & 4 & 2 & 3 & 1 & 1 / 3 & 4 & 2 & 7 & 6 \\
4 & 1 / 3 & 4 & 1 / 2 & 3 & 1 & 3 & 3 & 4 & 1 / 2 \\
1 / 2 & 1 / 3 & 1 / 3 & 1 / 7 & 1 / 4 & 1 / 3 & 1 & 5 & 2 & 1 / 3 \\
1 / 4 & 2 & 5 & 2 & 1 / 2 & 1 / 3 & 1 / 5 & 1 & 1 / 3 & 2 \\
1 / 5 & 1 / 4 & 1 / 5 & 1 / 2 & 1 / 7 & 1 / 4 & 1 / 2 & 3 & 1 & 1 / 5 \\
5 & 1 / 2 & 1 / 2 & 1 / 5 & 1 / 6 & 2 & 3 & 1 / 2 & 5 & 1
\end{array}\right)
$$

Criterion layer and layer judgment matrix table

(Scheme layer)

$$
\begin{aligned}
& B_{1}=\left(\begin{array}{ccccc}
1 & 2 & 2 / 3 & 1 / 3 & 1 / 2 \\
1 / 2 & 1 & 1 / 2 & 2 / 3 & 1 / 3 \\
3 / 2 & 2 & 1 & 3 / 5 & 2 / 3 \\
3 & 3 / 2 & 5 / 3 & 1 & 2 / 3 \\
2 & 3 & 2 & 3 / 2 & 1
\end{array}\right) \quad B_{2}=\left(\begin{array}{ccccc}
1 & 3 & 3 / 4 & 3 / 5 & 1 / 2 \\
1 / 3 & 1 & 1 / 3 & 1 / 5 & 1 / 6 \\
4 / 3 & 3 & 1 & 3 / 5 & 1 / 2 \\
5 / 3 & 5 & 5 / 3 & 1 & 5 / 6 \\
2 & 6 & 2 & 6 / 5 & 1
\end{array}\right) \\
& B_{3}=\left(\begin{array}{ccccc}
1 & 5 / 4 & 4 / 5 & 4 / 3 & 5 / 3 \\
4 / 5 & 1 & 2 / 3 & 3 / 5 & 2 / 3 \\
5 / 4 & 3 / 2 & 1 & 3 / 2 & 6 / 7 \\
3 / 4 & 5 / 3 & 2 / 3 & 1 & 2 / 3 \\
3 / 5 & 3 / 2 & 7 / 6 & 3 / 2 & 1
\end{array}\right) \quad B_{4}=\left(\begin{array}{ccccc}
1 & 3 & 3 / 2 & 5 / 4 & 5 / 8 \\
1 / 3 & 1 & 2 / 3 & 2 / 5 & 2 / 7 \\
2 / 3 & 3 / 2 & 1 & 3 / 5 & 3 / 7 \\
4 / 5 & 5 / 2 & 5 / 3 & 1 & 5 / 7 \\
8 / 5 & 7 / 2 & 7 / 3 & 7 / 5 & 1
\end{array}\right) \\
& B_{5}=\left(\begin{array}{ccccc}
1 & 6 / 5 & 3 / 2 & 7 / 4 & 4 / 5 \\
5 / 6 & 1 & 4 / 5 & 3 / 2 & 4 / 3 \\
2 / 3 & 5 / 4 & 1 & 5 / 3 & 6 / 7 \\
4 / 7 & 2 / 3 & 3 / 5 & 1 & 1 / 2 \\
5 / 4 & 3 / 4 & 7 / 6 & 2 & 1
\end{array}\right) \quad B_{6}=\left(\begin{array}{ccccc}
1 & 5 / 4 & 5 / 4 & 6 / 5 & 5 / 7 \\
4 / 5 & 1 & 2 / 3 & 3 / 4 & 1 / 2 \\
4 / 5 & 3 / 2 & 1 & 3 / 2 & 6 / 7 \\
5 / 6 & 4 / 3 & 2 / 3 & 1 & 5 / 7 \\
7 / 5 & 2 & 7 / 6 & 7 / 5 & 1
\end{array}\right) \\
& B_{7}=\left(\begin{array}{ccccc}
1 & 4 & 2 & 4 / 3 & 5 / 6 \\
1 / 4 & 1 & 1 / 2 & 2 / 3 & 1 / 3 \\
1 / 2 & 2 & 1 & 3 / 4 & 1 / 2 \\
3 / 4 & 3 / 2 & 4 / 3 & 1 & 2 / 3 \\
6 / 5 & 3 & 2 & 3 / 2 & 1
\end{array}\right) \quad B_{8}=\left(\begin{array}{ccccc}
1 & 2 & 4 / 3 & 2 & 4 / 5 \\
1 / 2 & 1 & 2 / 3 & 3 / 2 & 2 / 5 \\
3 / 4 & 3 / 2 & 1 & 4 / 3 & 3 / 5 \\
1 / 2 & 2 / 3 & 3 / 4 & 1 & 3 / 4 \\
5 / 4 & 5 / 2 & 5 / 3 & 4 / 3 & 1
\end{array}\right) \\
& B_{9}=\left(\begin{array}{ccccc}
1 & 3 / 4 & 3 / 5 & 5 / 4 & 2 / 3 \\
4 / 3 & 1 & 2 / 3 & 6 / 5 & 2 / 3 \\
5 / 3 & 3 / 2 & 1 & 2 & 4 / 3 \\
4 / 5 & 5 / 6 & 1 / 2 & 1 & 4 / 7 \\
3 / 2 & 3 / 2 & 3 / 4 & 7 / 4 & 1
\end{array}\right) \quad B_{10}=\left(\begin{array}{ccccc}
1 & 3 / 2 & 6 / 7 & 2 & 5 / 6 \\
2 / 3 & 1 & 4 / 7 & 4 / 3 & 2 / 3 \\
7 / 6 & 7 / 4 & 1 & 7 / 3 & 6 / 5 \\
1 / 2 & 3 / 4 & 3 / 7 & 1 & 1 / 2 \\
6 / 5 & 3 / 2 & 5 / 6 & 2 & 1
\end{array}\right)
\end{aligned}
$$


1). The level of single sort (weight vector) and inspection:

For experts to fill in after the judgment matrix, we use a certain mathematical method level.

Level single sorting refers to every judgment matrix of each factor in view of the relative weights of the criteria, so the level of single sort is essentially a weight vector. Calculated weight vector has the characteristic root method, and method, root method, power method, etc., and method is briefly introduced here.

And method principle is that the judgment matrix, consistency each column after normalization is the corresponding weights. For inconsistency judgment matrix, each column the approximate the weight of its corresponding normalized, in the $\mathrm{n}$ column calculating arithmetic mean as the final weight (Zhang, 2008).

The specific formula is as follows

$$
W_{i}=\frac{1}{n} \sum_{j=1}^{n} \frac{a_{i j}}{\sum_{k=1}^{n} a_{k l}}
$$

It is important to note that in layers of sorting when the consistency of judgment is matrix.

Matrix has passed judgment and consistency in exceptional circumstances. Under normal circumstances, we are not required to meet the strict nature of the judgment matrix. But look at the human understanding of the law, a right to judge the importance of the matrix is a certain logic to sort the law, for example, if A than B, B surpasses C importantly, from a logical perspective, A should be significantly more important than $\mathrm{C}$, if two a comparison of two important results than $\mathrm{C}$, then the judge violated the consistency criteria matrix , logically unreasonable occurs .

Therefore, in practice, we meet the general requirements of the judgment matrix consistency, the need for consistency checking. Only through testing, we can logically explain the judgment matrix is reasonable to continue to analyze the results.

Step consistency test is as follows

Step 1: Calculate the Consistency Index

$$
C I .=\frac{\lambda_{\max }-n}{n-1}
$$

Step 2: Look-up table to determine the corresponding average random consistency index

From the table, we get an average random consistency index RI. For example, for the fifth-order judgment matrix, look-up table RI $=1.12$

Step 3: Calculation of the proportion of consistency

$$
C . R .=\frac{C . I .}{R . I .}
$$

When $C . R<0.1$, we believe that the Judgment Matrix is acceptable. When $C . R<0.1$, we believe that the Judgment Matrix is acceptable. We need to re- amend the judgment matrix.

The total level of sorting and inspection:

Total ordering means that every judge the relative weight of each factor matrix for the target layer (top layer) of weight. The method used to calculate weights from the top down, layer by layer synthesis.

Clearly, a single sorting result of the second layer is the overall ranking results. Assumes that the k-1 layer is calculated first $\mathrm{m}$ elements of the target with respect to the total weight $\mathrm{w}^{(\mathrm{k}-1)}=\left(\mathrm{w}_{1}{ }^{(\mathrm{k}-1)}, \mathrm{w}_{2}{ }^{(\mathrm{k}-1)}, \ldots, \mathrm{w}_{\mathrm{m}}{ }^{(\mathrm{k}-1)}\right)^{\mathrm{T}}$, The element of the $k-n$ rank weight for single layer of ( Layer $k$ ) j-the element of the weight is $\mathrm{p}_{\mathrm{j}}^{(\mathrm{k})}=\left(\mathrm{p}_{1 \mathrm{j}}{ }^{(\mathrm{k})}, \mathrm{p}_{2 \mathrm{j}}{ }^{(\mathrm{k})}, \ldots, \mathrm{p}_{\mathrm{nj}}{ }^{(\mathrm{k})}\right)^{\mathrm{T}}, \mathrm{J}$ element which is not dominated by the right weight to zero. As $\mu_{0}$, Sort k layer represents the first element of the first k-1 layer elements, The first layer of the element k overall goals for total ordering is as follows (Zhu \& $\mathrm{Du}, 2008$ ).

$$
\mathrm{W}^{(\mathrm{k})}=\left(\mathrm{w}_{1}{ }^{(\mathrm{k})}, \mathrm{w}_{2}{ }^{(\mathrm{k})}, \ldots, \mathrm{w}_{\mathrm{n}}{ }^{(\mathrm{k})}\right)^{\mathrm{T}}=\mathrm{p}^{(\mathrm{k})} \mathrm{w}^{(\mathrm{k}-1)} \text { or } \mathcal{W}^{\left({ }^{(k)}\right.}=\sum_{j=1}^{m} p_{i j}{ }^{(k)} \mathcal{W}_{j}^{(k-1)} \quad \mathrm{I}=1,2, \ldots, \mathrm{n}
$$

Similarly, the need for overall consistency test results will be sorted. 
Supposed to have been calculated for the first k-1 layer j-the element of the guidelines C.I. ${ }_{\cdot j}{ }^{(k)} 、$ R.I. ${ }_{\cdot j}{ }^{(k)}$ and C.R. $\cdot{ }^{(k)}$, $\mathrm{j}=1,2, \ldots, \mathrm{m}$, is the first comprehensive assessment index $\mathrm{k}$ layer

$$
\begin{aligned}
& \text { C.I. }{ }_{j}{ }^{(\mathrm{k})}=\left(\text { C.I. }_{1}{ }^{(\mathrm{k})}, \text { C.I. }_{2}{ }^{(\mathrm{k})}, \ldots \text {, C.I. }{ }_{\mathrm{m}}{ }^{(\mathrm{k})}\right) \mathrm{W}^{(\mathrm{k}-1)} \\
& \text { R.I. }{ }_{j}{ }^{(k)}=\left(\text { R.I. }_{1}{ }^{(\mathrm{k})}, \text { R.I. }_{2}{ }^{(\mathrm{k})}, \ldots, \text { R.I. }_{\mathrm{m}}{ }^{(\mathrm{k})}\right) \mathrm{w}^{(\mathrm{k}-1)} \\
& C \cdot R .^{(k)}=\frac{C \cdot I .^{(k)}}{R \cdot I .^{(k)}}
\end{aligned}
$$

By MATLAB calculating

Table 16. The level of total order

\begin{tabular}{lccccccc}
\hline Criterion & & $\begin{array}{c}\text { Jungle } \\
\text { area }\end{array}$ & $\begin{array}{c}\text { Desert } \\
\text { region }\end{array}$ & $\begin{array}{c}\text { Mountainous } \\
\text { region }\end{array}$ & $\begin{array}{c}\text { Marine } \\
\text { region }\end{array}$ & $\begin{array}{c}\text { City } \\
\text { Region }\end{array}$ & $\begin{array}{c}\text { The total } \\
\text { order weight }\end{array}$ \\
\hline Weight of standard layer standards & 0.2344 & 0.0124 & 0.1349 & 0.31 & 0.3083 & 0.1473 \\
& Pattern 1 & 0.4611 & 0.1066 & 0.0246 & 0.2178 & 0.1899 & 0.2645 \\
& Pattern 2 & 0.2347 & 0.4211 & 0.12 & 0.172 & 0.0522 & 0.1345 \\
& Pattern 3 & 0.2321 & 0.2141 & 0.1013 & 0.1711 & 0.2814 & 0.2224 \\
Scheme of layer & Pattern 4 & 0.3411 & 0.2311 & 0.1005 & 0.0564 & 0.2709 & 0.1978 \\
of single rank & Pattern 5 & 0.1094 & 0.2645 & 0.1344 & 0.2478 & 0.2439 & 0.1755 \\
weights & Pattern 6 & 0.201 & 0.2644 & 0.0264 & 0.2714 & 0.2368 & 0.1245 \\
& Pattern 7 & 0.1079 & 0.2544 & 0.0578 & 0.4511 & 0.1288 & 0.1366 \\
& Pattern 8 & 0.191 & 0.3454 & 0.2011 & 0.0467 & 0.2158 & 0.1374 \\
& Pattern 9 & 0.023 & 0.3444 & 0.2016 & 0.2341 & 0.1969 & 0.0023 \\
& Pattern 10 & 0.3015 & 0.1013 & 0.1456 & 0.1782 & 0.2734 & 0.1277 \\
\hline
\end{tabular}

According to the total level results from the table, we draw dozens of camouflage pattern on the frequency of occurrence of the five roads.

Table 17. Ten camouflage patterns on the frequency of occurrence of the five road

\begin{tabular}{lllllllllll}
\hline & Pattern 1 & Pattern 2 & Pattern 3 & Pattern 4 & Pattern 5 & Pattern 6 & Pattern 7 & Pattern 8 & Pattern 9 & Pattern 10 \\
\hline Jungle area & $46.11 \%$ & $23.47 \%$ & $23.21 \%$ & $34.11 \%$ & $10.94 \%$ & $20.10 \%$ & $10.79 \%$ & $19.10 \%$ & $2.30 \%$ & $30.15 \%$ \\
Desert region & $10.66 \%$ & $42.11 \%$ & $21.41 \%$ & $23.11 \%$ & $26.45 \%$ & $26.44 \%$ & $25.44 \%$ & $34.54 \%$ & $34.44 \%$ & $10.13 \%$ \\
$\begin{array}{l}\text { Mountainous } \\
\text { region }\end{array}$ & $2.46 \%$ & $12.00 \%$ & $10.13 \%$ & $10.05 \%$ & $13.44 \%$ & $2.64 \%$ & $5.78 \%$ & $20.11 \%$ & $20.16 \%$ & $14.56 \%$ \\
Marine region & $21.78 \%$ & $17.20 \%$ & $17.11 \%$ & $5.64 \%$ & $24.78 \%$ & $27.14 \%$ & $45.11 \%$ & $4.67 \%$ & $23.41 \%$ & $17.82 \%$ \\
City Region & $18.99 \%$ & $5.22 \%$ & $28.14 \%$ & $27.09 \%$ & $24.39 \%$ & $23.68 \%$ & $12.88 \%$ & $21.58 \%$ & $19.69 \%$ & $27.34 \%$ \\
\hline
\end{tabular}

The jungle、 desert, mountains, ocean, city, these five terrain style were added to the total percentage of pattern $1-10$, we will have obtained and normalized as follows.

Table 18. Ten camouflage pattern in the proportion of all-terrain

\begin{tabular}{llllll}
\hline & Jungle area & Desert region & Mountainous region & Marine region & City Region \\
\hline $\begin{array}{l}\text { The proportion of } \\
\text { comprehensive Pattern }\end{array}$ & $22.03 \%$ & $25.47 \%$ & $11.13 \%$ & $20.47 \%$ & $20.90 \%$ \\
\hline
\end{tabular}

Based on the actual value F, we normalize and calculated for each class styles in the same environment and the proportion of the total style; 
Table 19. the percentage of the 10 pattern

\begin{tabular}{llllll}
\hline F value & Jungle area & Desert region & Mountainous region & Marine region & City Region \\
\hline Pattern 1 & $11.90 \%$ & $9.80 \%$ & $10.12 \%$ & $14.74 \%$ & $9.13 \%$ \\
Pattern 2 & $2.83 \%$ & $5.61 \%$ & $9.81 \%$ & $14.06 \%$ & $6.46 \%$ \\
Pattern 3 & $12.93 \%$ & $15.07 \%$ & $11.73 \%$ & $8.51 \%$ & $13.44 \%$ \\
Pattern 4 & $11.38 \%$ & $4.90 \%$ & $3.46 \%$ & $3.72 \%$ & $8.36 \%$ \\
Pattern 5 & $5.87 \%$ & $9.95 \%$ & $9.44 \%$ & $6.80 \%$ & $5.84 \%$ \\
Pattern 6 & $8.69 \%$ & $8.45 \%$ & $12.34 \%$ & $6.99 \%$ & $9.82 \%$ \\
Pattern 7 & $7.73 \%$ & $10.83 \%$ & $6.94 \%$ & $7.64 \%$ & $11.82 \%$ \\
Pattern 8 & $16.02 \%$ & $12.89 \%$ & $6.85 \%$ & $10.48 \%$ & $9.55 \%$ \\
Pattern 9 & $10.50 \%$ & $12.57 \%$ & $14.78 \%$ & $15.91 \%$ & $13.56 \%$ \\
Pattern 10 & $12.16 \%$ & $9.94 \%$ & $14.53 \%$ & $11.15 \%$ & $12.02 \%$ \\
\hline
\end{tabular}

We use the analytic hierarchy process to obtain the share of each type of terrain subjective weightings under the general terms; Finally, according to the weighted average method, we calculate the percentage of the ten camouflage patterns containing in the best pattern.

Table 20. the percentage of the 10 pattern in all Terrain

\begin{tabular}{llllll}
\hline Camouflage species & Pattern 1 & Pattern 2 & Pattern 3 & Pattern 4 & Pattern 5 \\
\hline Proportion & $11.17 \%$ & $7.37 \%$ & $12.54 \%$ & $6.65 \%$ & $7.49 \%$ \\
Camouflage species & Pattern 6 & Pattern 7 & Pattern 8 & Pattern 9 & Pattern 10 \\
Proportion & $8.92 \%$ & $9.27 \%$ & $11.71 \%$ & $13.25 \%$ & $11.62 \%$ \\
\hline
\end{tabular}

\section{Error Analysis and Improvement of Model}

\subsection{Error Analysis}

In examining the influence on the size of significant degree from the different patterns of color combinations, our viewing distance for different color combinations on different environments is a assumption that there is no use of optical instruments reconnaissance, and remove other external factors, ( such as visibility), we got the observation of a distance value $\mathrm{D}$ only by the naked eye. And in the actual situation $D=D_{0}+\Delta \mu, D_{0}$ Is the best ideal condition observation distance, and $\Delta \mu$ is the elastic range affected by the external environment change.

\subsection{Improvement}

Improvement 1: It's not realistic to regard the viewing angle as $0^{\circ}$ simply In the research about effect analysis of camouflage hiding ability of each styles of color combinations. In the study of practical problems, we should set a reasonable Angle, thus we will get different sizes of the significant degree, and the change or results will eventually affect the influence of different style color combination of camouflage to hide.

Improvement 2: When on the environment, the division into the jungle, desert, mountains, oceans, cities is too simple, you can choose other criteria, such as further subdivided typical environment, so that the results are more accurate and precise;

Improvement 3: There are still a lot of use demands for camouflage use demand, The model above model only regard color, brightness, complexity, correlation coefficient and significant level with its performance with as the use demand, in real life, the soldiers have requirements in the military camouflage and texture feature, shape feature and so on.

\section{Evaluation and Promotion for Models}

\subsection{Advantages}

Advantage 1: Related software supports, the results calculated are close to reality, high reliability; 
Advantage 2: as for problem one, in view of the reasonable model, the model considers from the characteristics of camouflage, it can accurately quantify the camouflage of the indicators, and it can greatly reduce the sample size, thus saved to a great extent, and quantitatively test the reliability of the model through the using of the software MATLAB ;

Advantage 3: Using the analytic hierarchy process to establish a hierarchical analysis model, sorting and consistency check in the single criterion, and made a total ordering, seek different styles of camouflage color combinations on the optimal all-terrain camouflage colors, the brightness, the complex the degree of correlation coefficient and a significant degree of combination, the actual results of the objective finally;

Advantage 4: Using the relative deviation fuzzy evaluation matrix and AHP combined, starting from the objective, subjective, with the actual situation, so the results of final design style of camouflage fatigues under different needs are more reliable.

\subsection{Disadvantage}

Disadvantage 1: Model ignores some minor factors in order to make the calculation simple and the results more idealistic as well;

Disadvantage 2: To meet the need of model analysis, we set five own performance of camouflage in the problem solving process, and conduct research through to camouflage's properties of different terrain, resulting in a large number of variables, the calculation process is difficult to converge, and sometimes only get partial optimal value instead of the global optimal value.

\subsection{Promotion}

Fuzzy evaluation method was founded on fuzzy math. Fuzzy technology can be applied to robotics, process control, subway locomotive, traffic management, fault diagnosis, medical diagnostics, voice recognition, image processing, market prediction and many other areas Fuzzy theory and fuzzy method have huge market potential and applications in the world;

Promotion of analytic hierarchy model: The decision method can be extended to many applications fields, such as: research evaluation, business valuation and personnel selection, etc.

This paper focused on the performance evaluation and analysis on camouflage of different color combinations as well as its optimal terrain. It has a very important practical significance in directing consumers to buy camouflage fatigues and manufacturers can select suitable camouflage uniforms according to their own needs for camouflage and frequently used terrain.

\section{References}

Chen, K. Q. (2014). Investigating on high spectral characteristics of camouflage clothing. Donghua University, Shanghai, China.

Han, Z. W., Wu, L. Y., Qiu, Z. M., \& Ren, L. Q. (2009). Microstructure and structural color in wing scales of butterfly Thaumantis diores. Chinese Science Bulletin, 2009.

Hou, L., Yu, J., \& Chen, D. (2013). Evaluation methods research on digital pattern painting. Foreign Electronic Measurement Technology, 2013(02)

Hu, J. H., Zhu, C., Wang, Y. J., \& Lu, J. Y. (2007). A method for detection and evaluation on pattern painting camouflage effect.China Measurement Technology, 2007(02)

Hua, W. S., Yang, J., Liu, X., \& Ma, Z. H. (2013). Camouflage assessment based on hyperspectral characteristics. Journal of Applied Optics, 2013(06)

Tu, Z. P. (2012). Digital Information Hiding Camouflage technology. Zhejiang University, Hangzhou, China.

Wang, Z., Yan, Y. H., \& Jiao, X. Y. (2013). Multi-index Comprehensive Evaluation of Camouflage Based on Gray Theory. Acta Armamentarii, 2013(10)

Xiao, M. (2006). Camouflage - the patron saint of soldiers. Civil Defence Realm, 2006(06).

Yang, W. X. (2011). Design Method spotted camouflage. Xi' an Technological University, Xi'an Chian.

Yuan, Z. M. (2008). Hyperspectral multi-angle study camouflaged fatigues. Northeast Normal University, Changchun, China.

Zhang, Y. (2008). Bionic Camouflage Digital Research and Technology. National University of Defense Technolog, 2008. 
Zhu, H. H., \& Du, S. D. (2008). Camouflage Assessment Based on Wavelet Texture Characteristics. Computer Engineering. 2008(16)

\section{Appendix}

The program of the grey statistics histogram

The programming of grey statistics histogram

img=imread('C: :Documents and Settings $\backslash J C S Y \backslash t a b l e l s e a . b m p ') ;$ $\mathrm{p}=\operatorname{rgb} 2$ gray(img);

$\mathrm{h}=\operatorname{imhist}(\mathrm{p})$;

$\mathrm{h} 1=\mathrm{h}(1: 2: 256)$;

$\mathrm{h} 2=1: 2: 256$;

stem(h2,h1,'r--');

figure,imhist(p);

The program of Analytic Hierarchy Process

$\operatorname{disp}()$;

$\mathrm{A}=$ input ('A $\mathrm{A}=$ ');

$[\mathrm{n}, \mathrm{n}]=\operatorname{size}(\mathrm{A})$;

$\mathrm{x}=$ ones $(\mathrm{n}, 100)$;

$\mathrm{y}=$ ones $(\mathrm{n}, 100)$;

$\mathrm{m}=\operatorname{zeros}(1,100)$;

$\mathrm{m}(1)=\max (\mathrm{x}(:, 1))$;

$\mathrm{y}(:, 1)=\mathrm{x}(:, 1)$;

$\mathrm{x}(:, 2)=\mathrm{A} * \mathrm{y}(:, 1)$;

$\mathrm{m}(2)=\max (\mathrm{x}(:, 2))$;

$\mathrm{y}(:, 2)=\mathrm{x}(:, 2) / \mathrm{m}(2)$;

$\mathrm{p}=0.0001 ; \mathrm{i}=2 ; \mathrm{k}=\mathrm{abs}(\mathrm{m}(2)-\mathrm{m}(1))$;

while $\mathrm{k}>\mathrm{p}$

$\mathrm{i}=\mathrm{i}+1$;

$\mathrm{x}(:, \mathrm{i})=\mathrm{A} * \mathrm{y}(:, \mathrm{i}-1)$;

$\mathrm{m}(\mathrm{i})=\max (\mathrm{x}(:, \mathrm{i}))$;

$\mathrm{y}(:, \mathrm{i})=\mathrm{x}(:, \mathrm{i}) / \mathrm{m}(\mathrm{i})$;

$\mathrm{k}=\operatorname{abs}(\mathrm{m}(\mathrm{i})-\mathrm{m}(\mathrm{i}-1))$;

end

$\mathrm{a}=\operatorname{sum}(\mathrm{y}(:, \mathrm{i}))$;

$\mathrm{w}=\mathrm{y}(:, \mathrm{i}) / \mathrm{a}$;

\section{Copyrights}

Copyright for this article is retained by the author(s), with first publication rights granted to the journal.

This is an open-access article distributed under the terms and conditions of the Creative Commons Attribution license (http://creativecommons.org/licenses/by/3.0/). 